\title{
DINÁMICA Y CAUTIVA: LA CULTURA MATERIAL DE LA CASA. UNA MIRADA ETNOGRÁFICA SOBRE EL HABITAR EN HAEDO, PROVINCIA DE BUENOS AIRES
}

\author{
María Florencia Blanco Esmoris* \\ flor.blancoesmoris@gmail.com \\ Centro de Investigaciones Sociales (CIS)-Instituto de Desarrollo Económico y Social (IDES) / \\ Consejo Nacional de Investigaciones Científicas y Técnicas (CONICET)-Buenos Aires, Argentina
}

\section{RESUMEN}

Este artículo busca problematizar, por un lado, la relación que establecen las personas con sus casas en la dinámica cotidiana. Esto es, cómo ocupan, decoran, usan y organizan los ambientes de la vivienda. Por otro lado, el objetivo es conocer cómo ese habitar se produce con relación a la localidad en donde viven: Haedo. Se apela a la cultura material en dos sentidos: de la vivienda y de los objetos que componen el habitar. Los datos surgen a partir de la etnografía que realicé entre 2015 y 2019 con la familia de Gloria, residente de Haedo. PAlabras Clave: etnografía, casa, cultura material, Haedo.

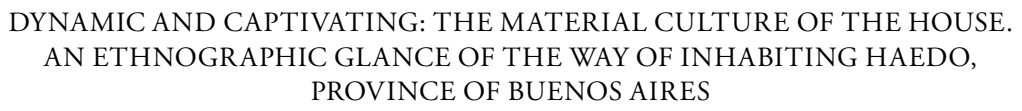

\section{Abstract}

This article aims to problematize, on the one hand, the relationship that people establishes with their homes in the daily dynamics. That is, how they occupy, decorate, use and organize the environments of the house. On the other hand, the objective is to know how this living is produced in relation to the locality where they live: Haedo. The material culture is appealed to in two senses: of the house and of the objects that compose the inhabitant. The data comes from the ethnography I made between 2015 and 2019 with the family of Gloria, a resident of Haedo.

KEYwORDs: ethnography, house, material culture, Haedo. 


\section{INTRODUCCIÓN}

La casa es a la vez lugar de salida y de llegada.

Pero ante todo es un lugar de distancia.

Incluso estando fuera de ella, cuando pensamos en la casa,

nos pensamos en ella (Ambriz Aguilar, 2009)

La casa atraviesa nuestras vidas. Con distintos matices y de forma variada, recorremos sus espacios, la apropiamos, la significamos, trazamos historias y memorias que quedan marcadas en sus paredes y su estructura; incluso tenemos lidias con ella. La exhibimos y, también, invitamos a otros a que la transiten. Trazamos continuidades y discontinuidades con sus espacios y los objetos que allí disponen. En materialidades más frágiles y fragmentadas, en algunas más robustas y transitables, nos aprehende y la aprehendemos. En suma, la habitamos.

A menudo damos por sentado no sólo la existencia de una casa -en la que vivimos-, sino que también homologamos nuestro vínculo con ella al que tienen otras personas, y no nos detenemos a interrogar las experiencias que surgen de/en ella. El interrogante respecto a la materialidad de la vivienda y en la vivienda excede el campo disciplinar de la antropología, tornándose de importancia para las ciencias sociales, humanidades, el urbanismo y la arquitectura. Por eso, propongo distintos lentes que, a lo largo del escrito, me permitirán ir haciendo zoom sobre el objeto de estudio: las características de la vivienda de Gloria y su habitar en Haedo (Provincia de Buenos Aires, Argentina).

Desde comienzos de siglo xx en Argentina, la vivienda moderna en sectores medios $^{1}$ era vinculada con la especificidad funcional de sus ambientes y con ciertas disposiciones de acuerdo con los cuartos, es decir, con la predefinición y segmentación de cada espacio - marcada por una fuerte normatividad-conforme al ideal de la familia nuclear mayormente difundido. Sin embargo, esto no resultaba una práctica usual en una sociedad cuya vida doméstica seguía organizada con base en una familia de tipo extendida (Aboy, 2008). Para mediados de siglo, un progresivo «achicamiento familiar» va a ser una planificación de largo plazo que incluirá diversos arreglos intrafamiliares tanto para acceder a la vivienda como para modificarla y mantenerla.

En este artículo, presento la familia de Gloria: una familia nuclear con una vivienda -como veremos- de extensiones amplias y que, de acuerdo con los materiales y el diseño arquitectónico, permite pensar otro abanico de experiencias y

* Esta investigación fue financiada por CONICET.

${ }^{1}$ En este artículo utilizaré el concepto de sectores medios ya que numerosos investigadores han dado cuenta de que la categoría problemáticamente ha sido empleada como objetiva y universal y que, al clasificar, ha tendido a homogeneizar las características de acuerdo con los criterios del investigador y experto (Visacovsky, 2008). Sin embargo, ocasionalmente la alusión explícita o implícita a la idea de clase media se escurre en los discursos y prácticas de las personas con las que realizo trabajo de campo. 
morfologías del habitar de quienes en la actualidad se reconocen dentro de los sectores medios. Asimismo, para reflexionar respecto a la elección de la vivienda resultan significativas las formas singulares y "globales» de ocupación, singularización y habitabilidad del espacio (Ballent y Liernur, 2014; Arizaga, 2017). Advierto entonces que en un escenario global y regional en donde los procesos identitarios parecieran concebirse como fluidos o sin apego (Castells, 2001) la vida continúa desarrollándose en "términos estrictamente locales» (Mc Dowell, 2000: 13), en este caso, entre la ciudad y la casa. En consecuencia, abordar el habitar me permite un acercamiento al mundo material y simbólico de ese homo quotidianus (Martínez, 2014: 6) de manera situada, abonando así a lo que Tim Ingold denominó la «perspectiva del habitar» (dwelling perspective) (Ingold, 1995). En esta línea, en Argentina existen antecedentes contemporáneos sobre la vivienda y su relación con el barrio (cerrado o abierto) en donde se encuentra, muchos de los cuales hacen foco en la Ciudad Autónoma de Buenos Aires (CABA)² (Arizaga, 2000; Wortman, 2001; Cosacov, 2017).

Cecilia Arizaga (2005), a partir de analizar los discursos publicitarios que exponen y circulan representaciones respecto del espacio doméstico, señala los nuevos agentes que se incorporan al mercado de la vivienda estableciendo las condiciones (objetos y usos) que marcan el «buen vivir» de las llamadas para comienzos de siglo xxi: las «nuevas clases medias». Arizaga destaca que dicho mercado se organiza alrededor de construcciones simbólicas que se imprimen tanto en las ciudades como en las casas. Algunas características que destaca la autora me interesa analizarlas por afuera del espacio geográfico de CABA, más específicamente en Haedo, localizado en el Gran Buenos Aires, área comúnmente denominada conurbano bonaerense ${ }^{3}$. Es en esta área de vacancia donde ubico mi trabajo. Me moviliza conocer aquellos condicionantes y posibilidades, objetivos y subjetivos, que atraviesan las experiencias y narrativas en la vida cotidiana de quienes residen en una vivienda, así como sus decisiones respecto a cómo se ha de habitar (Miller, 2001).

Este artículo es un desprendimiento de interrogantes más amplios que, en el marco de mi tesis doctoral, se interesan por los sentidos, usos y apropiaciones sobre y en la casa. Para este fin recupero notas de campo de mi investigación etnográfica de Gloria y su familia, quienes residen en la localidad de Haedo. Como presento a continuación, esta familia prescribe su habitar de acuerdo con su casa, su localidad y sus expectativas para vivir «bien». Me pregunto entonces ¿̨de qué manera, en la casa, las personas delimitan y negocian espacios y relaciones respecto a cómo se ha de habitar?

2 También denominada Capital Federal.

3 Existe una amplia literatura respecto a la definición del conurbano, cuyos límites de acuerdo con el criterio utilizado pueden variar considerablemente. Inicialmente, en el Censo de 1947, comenzó a utilizarse el término Gran Buenos Aires para referir a una unidad censal conformada tanto por la Ciudad Autónoma de Buenos Aires como por los municipios del Gran Buenos Aires que la rodean, en ese entonces 17, hoy 24 (Segura, 2015), también denominada Área Metropolitana de Buenos Aires (AMBA). En este trabajo, continuando con cierta tradición en la literatura académica consultada, hablamos de conurbano delimitado por los 24 municipios-partidos. 


\section{METODOLOGÍA}

Entre 2015 y 2019 realicé un trabajo de campo etnográfico en casas de familias, el cual privilegió la observación participante y la entrevista no directiva (Guber, 2001) como técnicas de generación de conocimiento. Este fue efectuado en diversas casas de familias que se autoperciben y autoadscriben como parte de los sectores medios - a menudo aludiendo a la noción de "clases medias»- residentes en Haedo y sus inmediaciones (Municipio de Morón, Gran Buenos Aires, Argentina). Mi ingreso a cada casa fue mediado por las mujeres. Como mencioné anteriormente, para este artículo, presento a Gloria y su familia ${ }^{4}$.

Incorporarme a la vida cotidiana y al espacio íntimo supuso identificar aquellos canales de confianza que podían auspiciar de llave para el acceso etnográfico en las casas. Por lo que mi estrategia metodológica se centró en activar mis círculos de afinidad. En particular, vinculados a mi escolarización en un colegio considerado, con razón a su antigüedad, "tradicional» en la zona y de orientación religiosa católica y de gestión privada (localizado en El Palomar) $)^{5}$. Esta estrategia me permitió armarme de una red de contactos para comenzar el trabajo de campo. De esta manera, el colegio se convirtió en "portero" para acceder a estas familias. Con relación a Gloria, como exalumnas, participamos desde el año 2009 del mismo espacio de entrenamiento de hockey sobre césped.

La delimitación de esta familia surge a partir de ciertos observables que me permitieron establecer una aproximación heurística a los sectores medios en la zona trabajada. Estos observables (extensión y estética de la casa, la zona en la que se sitúa, la escolaridad de sus hijos y su tipo de gestión, el acceso a servicios de salud, entre otros) se complementaron con algunas dimensiones como ocupación e ingreso ${ }^{6}$. Mis entradas al campo fueron, en algunos casos, semanales -incluso alcanzando una frecuencia de tres veces por semana- $y$, en otros, quincenales o mensuales de acuerdo con el momento del año. Esta temporalidad se vio signada por eventos cotidianos, imponderables y otras circunstancias de la organización familiar. Con el correr de los meses y los años fui formando parte de variadas situaciones y eventos (como el día de la madre, cumpleaños, entre otros) que me permitieron asir lo relacional en lo material. En ese sentido, notando cómo los límites se tornaban móviles y dinámicos, anclados no sólo en los objetos, sino en las prácticas que los (re)actualizaban

${ }^{4}$ Cabe señalar que esta familia puede incorporarse a los sectores medios de acuerdo con diversos criterios socioeconómicos (como los de ingresos, su nivel educativo, sus accesos a servicios de salud de gestión privada, características de la vivienda, aprovisionamiento, entre otras características).

5 Este colegio cuenta con nivel maternal y jardín, primario, secundario y escuela técnica. Se ubica en la localidad de El Palomar, lindante con la localidad de Haedo. Se fundó en 1954 por un padre alemán y hoy en día su matrícula asciende a los/las 2500 estudiantes.

${ }^{6}$ El nivel de ingreso mensual de este hogar supera hasta más de tres veces el ingreso promedio relevado para aglomerados urbanos (Bonfiglio et al., 2008). Para el momento en que se realizó el trabajo de campo, según este informe, el nivel de ingreso total familiar para el estrato socioeconómico medio alto era de \$36347 para diciembre de 2016 . 


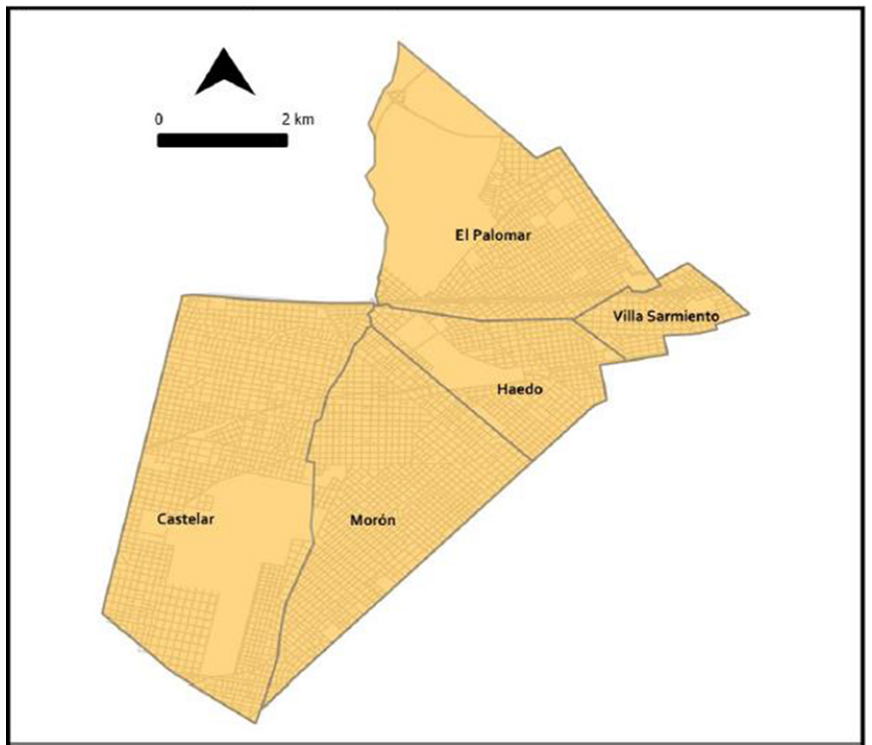

Fuente: Acumar. Límites municipales: Av. Presidente Perón, Colihue, Cańada de Juan Ruiz, Rawson, Pueyrredón, Don Bosco, Fray Cayetano Rodríguez, Av. Rivadavia, Güemes.

y los significaban. La cotidianidad puede parecer que no encierra artilugio alguno; sin embargo, se presenta como un «escenario en donde se multiplican los efectos» (Balandier, 1994) y las formas de habitar la casa a través de la objetos, bienes y artefactos entendidos en tanto cultura material ${ }^{7}$ y sus articulaciones con la localidad.

\section{HABITAR HAEDO, VALORAR SUS RITMOS ${ }^{8}$}

Haedo no es un pueblo. Es una ciudad. No tiene subtes, no tiene cadenas de gimnasios y en la actualidad no tiene boliches. Está localizada dentro del Municipio de Morón (mapa I) y lindante con los municipios de La Matanza, Ituzaingó,

7 Sobre la cultura material cabe decir que, si bien inicialmente dentro de la antropología estuvo fuertemente articulada con la práctica arqueológica e incluso en los primeros pasos de la antropología moderna al método evolucionista -que clasificaba las culturas a partir de sus «vestigios»-, en las últimas décadas renovadas relecturas y novedosos aportes han dado cuenta de la importancia de retomar tal agenda que había quedado relegada desde las primeras décadas del siglo xx. En particular puede consultarse Miller $(2001 ; 2005 ; 2008)$, quien arrimó trabajos empíricos en torno a la vida cotidiana y a las casas en diversas ciudades de Londres.

${ }^{8}$ Algunas descripciones que se expresan en este apartado fueron presentadas en otro artículo de mi autoría, Blanco Esmoris (2019). 
Merlo, Hurlingham y Tres de Febrero. Dentro del Municipio de Morón encontramos las localidades de Morón, Villa Sarmiento, Castelar, Haedo y El Palomar.

El nombre de esta localidad es en conmemoración a Mariano José Haedo, presidente de la Comisión Directiva del Ferrocarril del Oeste, que decide crear una estación empalme en esa tierra por $1887^{\circ}$. La piedra fundamental que le dio inicio se colocó en 1889. Para ese entonces, Haedo era un pueblo de veraneo de las familias de Buenos Aires, con grandes casas quintas. A principios de siglo, junto con Ramos Mejía, eran los lugares de descanso y retiro de la ciudad. Y, al mismo tiempo, como lo señalaba una edición del periódico La Tribuna en agosto, 1967, Haedo a principios de siglo se consolidaba como un punto neurálgico de las comunicaciones ${ }^{10}$. Tras el golpe militar de 1930 Haedo se vio -paradójicamente- «revitalizada» por el gobernador Manuel Fresco ${ }^{11}$, quien va a elegir una antigua casona ubicada en esta localidad para residir ${ }^{12}$.

Con el correr de las décadas, Haedo fue incorporando a su trama urbana casas y locales comerciales. Para fines de los sesenta se emplaza la Universidad Tecnológica Nacional (UTN), cercana al Parque Industrial «La Cantábrica», y a mediados de los setenta nace la Biblioteca Pública de Haedo tras una iniciativa de una asociación civil vecinal. En Haedo se encuentran las estaciones del tren General Roca y la línea General Sarmiento, un centro comercial -centrado en la avenida Rivadavia y que continúa en sus inmediaciones-, algunos colegios, un shopping-Al Oeste- y al menos una decena de líneas de colectivos la atraviesan. El Club Sportivo Haedo (CASH) y el Club Haedo Juniors, junto con la Sociedad de Fomento Haedo Sur, llevan en su nombre la localidad. Si bien la proliferación de casas y cierto «boom inmobiliario" puede ser anticipado desde la década del ochenta, en los últimos 20 años se percibe una intensa actividad inmobiliaria (Clarín, 26-07-2005) ${ }^{13}$. Con más de 35000 habitantes, según el último censo, efectuado en 2010 ${ }^{14}$, en Haedo también encontramos una delegación municipal, la Unidad de Gestión Comunitaria (UGC 2), que en los discursos y las prácticas de las personas pasa desapercibida.

En Haedo, algunas casas -las más antiguas- se caracterizan por ser de dos plantas, tener jardines delanteros y ladrillos a la vista. Otras construcciones, posteriores y más pequeñas, se destacan por sus tejados a dos aguas, sus paredes de cemento alisado y sus puertas de madera maciza. Aunque en menor cantidad, también hay

9 Municipio de Morón, información respecto a la localidad de Haedo, disponible en http:// www.moron.gob.ar/municipio/localidades/haedo/.

${ }^{10}$ En La Tribuna, agosto 1967, especial por Norberto P. Devoto «Haedo, 1902».

11 En el marco del golpe de Estado de 1930 y bajo un proyecto presentado por el senador Dr. Obregón, el gobierno provincial aprobó el cambio de nombre a "Seis de Setiembre» en honor al día en que el golpe militar derrocó al presidente Hipólito Yrigoyen; el nombre Morón será restituido a la localidad en 1946 bajo la intendencia de César Albistur Villegas.

12 Hoy cedida a un centro cultural autogestivo denominado «El Transformador».

13 L. Ceriotto, «El boom inmobiliario llega al interior», Diario Clarín, 26 de julio de 2005, sección Noticias.

${ }_{14}$ Municipio de Morón, disponible en http://www.moron.gob.ar/municipio/localidades/ haedo/. 
edificios, ubicados en el centro comercial, mayoritariamente frente a la estación. Por otra parte, las unidades constructivas más recientes se caracterizan por tener paredes de hormigón alisado pintadas con colores pasteles, techos de chapa galvanizada color negro y -a diferencia de los chalets más antiguos- sin tejas, y entradas a la calle caracterizadas por sus portones metálicos en color gris topo. En la actualidad, Haedo es una de las tres localidades del conurbano oeste que, junto con Ramos Mejía y Castelar, en las últimas décadas han devenido en "altamente valoradas» (Kamitz, 2015) por la industria inmobiliaria y el mercado del suelo, alcanzando valores por metro cuadrado similares a los de las localidades del Corredor Norte de la Provincia de Buenos Aires ${ }^{15}$. Este reciente "boom inmobiliario» ${ }^{16}$ ha hecho de esta localidad un atractivo para situarse fuera de la ciudad - pero un acceso a la misma garantizado- y con un estilo de vida "más saludable» (Kamitz, 2015). Esta localidad se exhibe como un "polo residencial» emergente para los sectores medios (Kamitz, 2015: 12), ya manifiesto y explícito desde el 2001. El ritmo de esta localidad se desacelera cuando cae la noche, momento en el que un par de restaurantes, un bar, la estación de servicios y una casa de comidas rápidas mantienen vida. En mi investigación, noté que la vinculación de la localidad con el municipio presentaba matices y formas variadas en donde lo geográfico y lo moral parecían asirse. Esto es, que las fronteras morales también eran ancladas geográficamente. Algunas delimitaciones al interior de la localidad identificadas por mis interlocutores son Haedo Sur, Haedo Chico/Residencial y Haedo Norte ${ }^{17}$ (véase mapa II). En particular, como veremos, para Gloria «Haedo Chico» configura su medio, que le da «seguridad».

Como en otras localidades, en esta también los agentes comerciales y las personas precisan distinciones conforme tanto a la infraestructura material de la ciudad como a lugares que son significativos en sus circulaciones cotidianas; para Gloria, esto involucra límites precisos como el túnel, la barrera, la avenida, "Gaona", la autopista, El Colegio, entre otros. En mi trabajo de campo, estos límites, poco a poco, comenzaban a marcar una serie de territorios morales, sentidos y valoraciones asociadas a esos puntos geográficos. En algunos casos, a partir de binomios: frente a un Haedo «bien y seguro» contraponían la localidad de Morón -localidad cabecera del municipio (ver mapas I y II)- como un espacio «inseguro y peligroso». Ahí noté que la misma ciudad presentaba fragmentaciones, al menos, para algunas personas y sus usos. De esto se desprendía una forma de habitar el espacio urbano donde la localidad tenía su correlato en las casas y sus narrativas. Mientras para

15 En este caso, Haedo y Ramos Mejía, con un precio por $\mathrm{m}^{2}$ del terreno entre los U\$S 550 y U\$S 760, similar a aquellos valores de los terrenos en localidades del Corredor Norte, tales como Martínez (U\$S 692,0) o Acassuso (U\$S 616,0), ambas en el Partido de San Isidro (Informe de Distribución Territorial del Precio de Oferta, 2014: 17 y ss.).

16 Diario Clarín 2005. «El boom inmobiliario llega al interior: en el sur y oeste del GBA también aumentaron los precios de departamentos», noticias, 26 de julio.

17 Los límites de zonas de acuerdo con el municipio pueden consultarse en Límite municipal: Honorable Consejo Deliberante, disponible en http://www.hcdmoron.gov.ar/cou/codigo/limiteszonas.html. 




Fuente: elaboración propia con la información provista desde el Municipio de Morón y precisiones de mis interlocutores.

algunos Haedo es una transición para ir a otros puntos del conurbano bonaerense o para ir a CABA, para otros, el lugar donde viven. Gloria ${ }^{18}$ pertenece al segundo grupo. Ella y su familia viven a unas 12 cuadras de la estación de Haedo, a 6/7 de avenida Rivadavia, en la zona denominada como Haedo Chico. Justamente, para Gloria, Haedo es parte de su «ser en el mundo».

Gloria vive en Haedo «desde siempre». Nació el 26 de enero de 1976, tiene una hermana -que vive con su familia en Ciudad Autónoma de Buenos Aires (CABA) - y un hermano -vive en Italia- y fue a un colegio católico de gestión privada ubicado en la localidad de El Palomar. De joven jugó al hockey en el colegio y en el Club San Martín. Estudió en un terciario la tecnicatura en Estudios ambientales, pero hoy en día se dedica «a la casa y a los chicos». Recientemente inició junto con una amiga un emprendimiento de venta de ropa deportiva. Está casada con Ariel, oriundo de Haedo, quien durante el secundario fue al mismo colegio que Gloria. También nacido en el 76, vivió a tres cuadras de la clase de Gloria, además de compartir un grupo católico denominado Partida. Ariel trabaja en la industria del

18 Todos los nombres son ficticios a fin de preservar la identidad de los actores. A Gloria la conozco desde el año 2009, en que se comienza a armar un grupo de hockey de madres y exalumnas. 
hormigón, es independiente y tiene una fábrica en zona norte. Aunque Ariel no es ni arquitecto ni ingeniero, siempre le apasionó lo artesanal; como me dijo Gloria, «aprendió de mirar a su papá arreglar la casa». Su experiencia religiosa en el grupo Partida -donde conoció a su marido-, ser parte de una sociabilidad tradicional en Haedo, transitar por espacios con «valores»-como el colegio al que acudió- expresan en ella y en su familia vínculos estrechos en la significación de lo local y de su casa.

Camino a su casa, paso por una verdulería, un supermercado chino, una clínica privada, una casa de pastas y un almacén. El barrio está en silencio, algunas personas están en la vereda, barriendo o cruzando con bolsas cargadas de mercadería. «No podría vivir en otro lugar», me había dicho Gloria hace algunas semanas. Resulta que, para ella, así como para algunos miembros de su familia, su entorno y vida social están allí, a lo sumo en localidades aledañas como Ramos Mejía-Palomar (donde ella, Ariel y hoy día sus hijos van al colegio) -Morón-. Gloria y su familia van -casi- exclusivamente al centro -Capital Federal- para ver a su hermana, que vive en el barrio de Palermo. Para ella el centro es caótico, «un bardo», esto no es nada nuevo. Creo que cualquiera que va $-y$ no necesariamente vive- al centro, más específicamente el micro, seguramente haya pensado lo mismo que Gloria. Para ella Haedo implica cierta tranquilidad que no se logra en la gran ciudad. Para ella el centro es todo uno, no hay gradientes, así como tampoco categorías intermedias, Gloria va delineando un conjunto de oposiciones homólogas: Centro-caótico/ Haedo-tranquilo. Para Gloria en Haedo la gente es «más amigable» y corre con la ventaja de que "se conocen todos»; por momentos me da la sensación de que para Gloria hay cierta contigüidad entre Haedo y su casa. En este escenario viven Gloria (41) y Ariel (41), con sus tres hijos: Nicanor (14), Lola (11) y Santiago (7) [registro de campo, noviembre 2015].

\section{MORAR EN HAEDO: LA CASA DE GLORIA}

Del latín morari, morar remite a permanecer y residir, pero también al obrar con lentitud. Si desde mediados de siglo xx en Argentina la vivienda moderna en sectores medios era vinculada a la especificidad funcional de sus ambientes, una normatividad del espacio y una llamada de atención sobre su transgresión (Pérez, 2012), hoy en día, en las diversas casas en las que me encuentro haciendo trabajo de campo, observo formas singulares y "globales» de la apropiación, ocupación y habitabilidad del espacio. De forma práctica emergieron algunos interrogantes que me permitieron organizar este apartado: ¿qué formas de diseño arquitectónico se presentan?, ¿cómo se organizan el tiempo y el espacio en el hogar?, ¿¿de qué manera nuevos objetos irrumpen la escena cotidiana?

Según la Real Academia Española (RAE), la primera definición de casa es «edificio para habitar»" . A su vez, la misma entidad prescribe inicialmente hogar

${ }_{19}$ Real Academia Española (RAE), disponible en http://dle.rae.es/?id=7lsKMtR. 
como «sitio donde se hace lumbre en las cocinas, chimeneas, hornos de fundición, etc. $\nu^{20}$. Mientras la primera supone prescribir la estructura edilicia, la segunda remite a una congregación alrededor del fuego. Aun cuando para arquitectos, urbanistas, agentes inmobiliarios y el mismo municipio casa parece limitarse a la designación de la RAE, los usuarios utilizan la misma palabra para designar múltiples cosas que exceden su materialidad. Hogar no es ni una categoría nativa ni una forma efectiva de referir a sus casas.

Hace más de seis años que Gloria y Ariel compraron un amplio terreno a tan sólo unas cuadras de una propiedad horizontal $(\mathrm{PH})^{21}$ de la familia de Ariel en donde vivieron mientras criaban a sus primeros dos hijos. Tras la compra, edificaron una casa y se mudaron. Recuerdo que llamó mi atención apenas la visité, pues su geometría y su escala cromática sólo iban del blanco al gris. La casa es de grandes extensiones y ambientes amplios. Es lo que podría denominar «minimalista», tiene colores monocromáticos y texturas simples. En arquitectura, el minimalismo se vincula al concepto iniciado por el arquitecto y diseñador industrial Ludwig Mies van der Rohe (1886-1969) de "menos es más», fundamentalmente difundido a finales de la década del sesenta y caracterizado por materiales como el cemento, la piedra, el acero, el vidrio y la madera. Justamente, la idea es evitar el «exceso» en la construcción.

Al frente, hay una puerta para el acceso de personas y otra para el ingreso de autos, en el estacionamiento entran dos autos (en ese momento sólo estaba la camioneta familiar Suran de Volkswagen, que es la que utiliza ella). Se ingresa a través de una pesada puerta de madera de casi 3 metros de alto y 2 de ancho. Es un rectángulo que, si bien en términos analíticos podría dividir en dos partes arriba/ abajo-adentro/afuera, parecen fundirse - dado su estilo arquitectónico-. La primera de ellas es el ambiente cerrado - «la casa» propiamente dicha- (plano I), si algo la caracteriza es la falta de paredes, todo está a la vista y los lugares pueden ser circulados por cualquier persona. La otra parte es el afuera: el deck, el patio, la pileta y el quincho. Todo el perímetro de la casa está monitoreado por cámaras de seguridad que se pueden monitorear desde la cocina.

¿Qué cosas de esa casa habían llamado mi atención? Llamó mi atención la falta de divisiones/fragmentaciones edilicias -que en mí ya eran naturales- bajo las cuales había transitado mi propia experiencia biográfica. Automáticamente, pensé en mi casa, ubicada a unas 20/25 cuadras de lo de Gloria, en el partido de La Matanza, en donde los espacios de la casa no sólo eran más reducidos, sino que las paredes delimitaban dicha funcionalidad, así como a las personas. La normatividad y la restricción a las distintas habitaciones eran parte del cotidiano. En mi casa predominan las divisiones y materiales como la madera. Sus colores oscuros la

${ }^{20}$ Real Academia Española (RAE), disponible en http://dle.rae.es/?id=KYIGBW2.

${ }^{21}$ En Argentina, las propiedades horizontales, mayormente sintetizadas con la sigla $\mathrm{PH}$, constan de un inmueble en planta baja con un pasillo común que comunica las viviendas. En términos legales implica la situación dominal compartida con condóminos (dueños/as). 


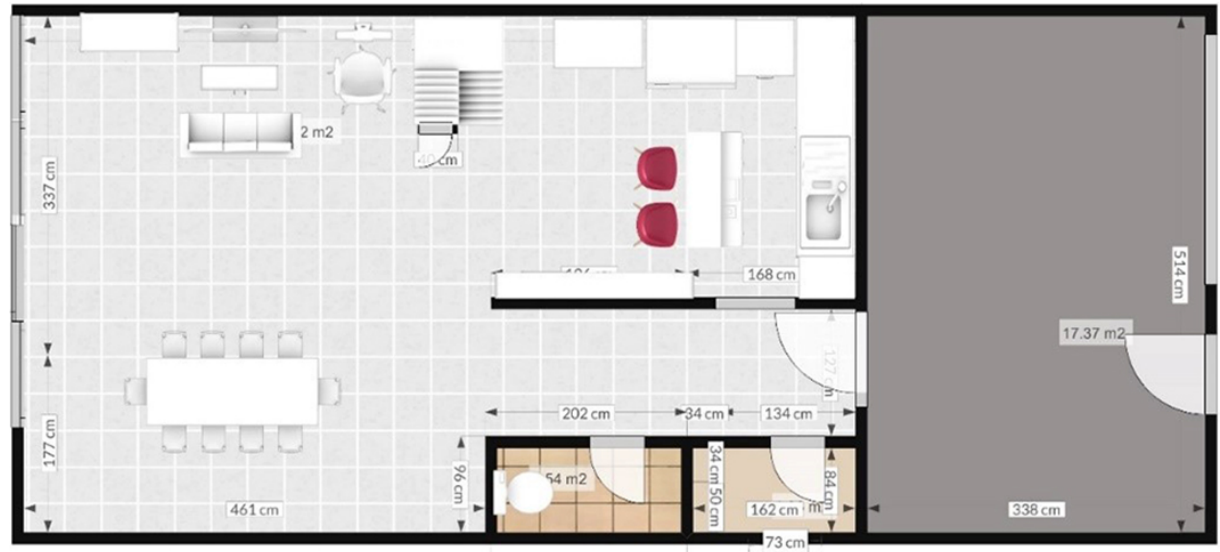

Fuente: elaboración propia en base a observación. Programa Homebyme.

hacen más lúgubre. De ladrillos a la vista, mis padres la habían construido durante la primera mitad de la década del noventa. La casa de Gloria, edificada a fines de la primera década del 2000, parecía tener otras reglas y funcionalidades, así como tonalidades. Una casa que deja la compartimentación y se torna un único espacio. Allí donde suponía «muros» había ambigüedad, equívocos y porosidad. La producción del espacio y su delimitación parecían balancearse de acuerdo con el lugar, el asunto, los actores, así como el sentido otorgado.

Entonces, a mi entender, en la casa de Gloria no había «medias tintas»: no había cortinas -que tapen parcialmente-, no había paredes -en la planta baja-, todo estaba a la vista y, en este caso, no eran los ladrillos sino los juguetes, el material de trabajo, la comida, los útiles, la tecnología y lo artesanal; todo era parte de uno. Entonces, ¿cómo comprender una espacialidad que a priori presentaba más continuidades que discontinuidades edilicias?

Poco a poco fui incorporándome a la materialidad de la casa. La planta baja, abierta y transitada, es de recepción y permanencia. Encarna un espacio privado pero permitido. Sus muebles son nuevos, de colores claros. Al entrar de mano izquierda hay un pequeño cuartito en donde dejan abrigos, camperas, palos de hockey, zapatillas. El cuarto que le sigue es un baño. Contiguo a este, hay un amplio ambiente, algunos le dirían la living-comedor, en donde hay una robusta y maciza mesa de madera con sillas para 10-12 personas que marca un espacio formal para las comidas. Allí, Gloria y su familia comparten las comidas diarias (más frecuentemente cenas), así como los eventos familiares y extrafamiliares. En invierno las cenas se hacen allí, mientras que en verano es reemplazada por la mesa ratona del deck en el exterior de su casa con vista a la pileta. Del lado izquierdo, al costado de la mesa, hay un cuadro - cedido por su hermana- de fondo blanco y con "personitas» dibujadas en los colores rojo y negro. Gloria me contó que se lo había regalado su hermana y que ella justo tenía ahí el cable del aire y le servía para tapar todo eso 
(el cuadro tiene un fondo blanco y personas de distintos tamaños están haciendo diferentes cosas, están pintadas de color negro y por momentos hay trazos en color rojo). El uso del cuadro para Gloria no remitía tanto a patrones estéticos, sino a una forma práctica de resolver, ocultar aquel cable del aire acondicionado. Al derecho de la gran mesa, un futón, la mesa ratona, la tele frente al futón, la computadora en un extremo demarcan -de forma más o menos estricta- lo que sería el living. Hay dos consolas de videojuegos (PlayStation y una Wii), equipo de sonido que acompañan la televisión de pantalla plana-de más de 50 pulgadas-, un objeto de disputa entre los hijos de Gloria y Ariel. Tienen televisión por cable y Netflix. Ariel suele mirar tutoriales por internet, para bajarse unos programas, habla con Nicanor sobre fútbol -miran a River Plate- y/o se dedica a arreglar o a hacer algo para la casa. En el living, muchas veces se sientan los invitados; es un lugar distendido, el orden no es la regla, sí en cambio la comodidad y la disponibilidad de todo, no sólo para los chicos, sino para quien lo necesite. Gloria te indica dónde está cada cosa, te describe el espacio y el objeto, y te da su aval para que vayas a buscarla. Cada invitado es un poco anfitrión, la idea es que esté todo dispuesto y disponible. En el living, se encuentran lo cercano y lo nuevo, sea un invitado a la casa como una compra en materia de tecnología; la disposición y adquisición de bienes es variable. El uso del living se vincula de manera casi exclusiva al sillón, la mesa ratona, la tv, los videojuegos y la computadora a un costado. Este espacio suele ocuparse por Ariel, Nicanor, Lola, Santiago y Ariel más que nada luego del mediodía, horario en que los hijos de Gloria y Ariel regresan de su escolaridad, y en las tardes-noches cuando regresa Ariel del trabajo.

Al subir las escaleras está la planta alta de la casa. Allí hay dispuestos dos baños, tres cuartos habitables (uno para Ariel y Gloria, otro para los hijos varones y uno para Lola) y uno de servicio -en donde está el lavadero-. Hay una claraboya desde la cual se puede ver el cielo. El diseño se continúa en concordancia con la planta baja en cuanto a colores (blancos y grises -en los espacios de transición-) y terminaciones. El cuarto de Ariel y Gloria tiene muebles de madera, cama tipo sommier, posee un baño en suite y predominan los colores claros en las paredes, que hacen contraste con la cama.

\section{CONTINUAR LA ESPACIALIDAD, SEGMENTAR SUS USOS}

En la parte baja, en la cocina, predominan los tonos grises, el negro, blanco y el rojo. Hay en medio una «isla» con las hornallas y un desayunador integrado. Es uno de los lugares privilegiados de Gloria, donde pasa tanto la mañana, la tarde y la noche.

Recuerdo la primera vez que ingresé a su cocina, parecía de revista, Gloria me dijo que era de Johnson. Yo no entendía mucho de cocinas. Busqué un poco y leí que Johnson se dedicaba a la fabricación de cocinas industriales y se las vendían a espacios con una producción intensiva y de grandes volúmenes y que posteriormente comenzaron a trasladarse al ámbito doméstico y, por tanto, cotidiano. Según la 
web institucional ${ }^{22}$, es una empresa dedicada específicamente al acero y luego se expandió al amueblamiento con "soluciones para mejorar el confort y la calidad del hábitat». Para Gloria, esa marca sintetizaba muchas cosas, entre ellas el «buen cocinar» [registro de campo, agosto 2015].

La cocina es un espacio que no sólo alberga momentos de alimentación, sino que también propicia un lugar de charla, tarea, juego y variadas cosas. La cocina, para Gloria y Ariel, se vuelve sinónimo de práctica, más aún su mesada-desayunador. La cocina se encuentra equipada con una cuantiosa e interesante cantidad de artefactos. Cuenta con una heladera de puerta doble con una mesada de mármol, lavavajilla, horno, microondas, la máquina de café expreso -Nespresso- con algunas capsulas exhibidas al costado sobre una mesada (frente a la isla) en donde está la bacha, también hay una pecera con una tortuga («Tortu»), un monitor por el que regula las cámaras de la casa, y el teléfono inalámbrico. La relación entre tecnología, alimentación y aprovisionamiento es intensa y continua. En el quincho, poseen un freezer donde conservan alimentos y bebidas, así como otras cosas de la casa. Cuando hay algún acontecimiento, previsto o imprevisto, el quincho es garante del aprovisionamiento. En sus compras mensuales destinan tiempo, presupuesto y espacio para sus adquisiciones. La improvisación no parece ser la regla.

Dentro de este espacio, la máquina de Nespresso (que combina una marca Nescafé y un tipo de café Expresso) llamó mi atención, menos por su exclusividad ${ }^{23}$ y más por la regularidad con la que la veía en distintas casas de amigos/as por esa localidad. Respecto al café en general y al boom de la máquina de expreso, encontraba que este tipo de comercialización -en monodosis y con distintos sabores- remitía no sólo a una forma de "empujar al consumo", sino de llamar la atención respecto a una "sofisticación» del gusto ${ }^{24}$. En este sentido, el hogar comenzaba a presentarse como una suerte de escenario en donde se dan a conocer objetos y adquisiciones (Miller, 2001: 2008), que permiten clasificar(se) en un mundo social deseado sobre el que empiezan a tener injerencia otros.

Gloria divide el tiempo ordinario en «con los chicos y sin los chicos». En el momento en que no están los chicos, es tiempo de limpieza, de quehaceres del hogar -ya que la persona que se encarga de la limpieza renunción ${ }^{25}$, sale a comprar lo que hace falta (normalmente a los almacenes del centro de Haedo) y, ahora, dedica parte de su tiempo a un emprendimiento. Después de buscar los chicos al colegio, prepara el almuerzo, habla con ellos, organiza los turnos con los médicos, lava, entre

${ }^{22}$ Cocinas y revestimientos Johnson. Puede consultarse mayor información en su sitio de comercialización: http://www.johnsonacero.com/.

${ }^{23}$ Aunque sus valores iniciales superan los $\$ 2000$ por artefacto, para el tipo de cambio oficial al 31 de agosto de 2015, en Argentina serían USD 215.

${ }^{24}$ Apellido de café, entrevista a Martín Cabrales -tercera generación de la empresa líder del rubro- en Infonegocios, 3 de junio 2013.

${ }_{25}$ Gloria me contó que la causa de su renuncia fue porque tenía que quedarse ayudando a su hermana embarazada. 
muchas otras cosas. Gloria divide el tiempo que comparte con Ariel como «en zona norte [en su trabajo] y acá [en su casa]». Así, el espacio se vincula con Gloria en una triple función: esposa, madre y emprendedora.

Si la barra-desayunador- parece un accesorio, esto no es así en la práctica. En el tiempo ordinario (lunes a viernes al mediodía, algunas noches), la barra de la cocina es la mesa principal, es decir, que hay un uso normalizado. En el tiempo extraordinario (cumpleaños, día de la madre/padre, celebraciones) la barra se utiliza para los preparativos, y la robusta mesa del comedor, para disponer todos los comestibles y bebibles para disfrutar del encuentro. La parte baja de la casa es un espacioso y luminoso único ambiente que se conecta con la cocina, como un continuum. En la parte baja de la casa, transita la familia, los amigos e invitados, es un espacio de recepción, circulación y permanencia. Los amplios ambientes facilitan eso. No hay divisiones claras impresas en la arquitectura, más bien esas divisiones se apoyan en los objetos allí posicionados: mesa, futón, dispositivos de entretenimiento. No hay división entre un living y un comedor, así como no la hay entre luz y oscuridad.

En la parte alta, hay divisiones, paredes y puertas. El tránsito es menor, no suben los invitados, sólo algunos amigos de la familia y familiares lo hacen. Es el lugar de la intimidad y del descanso. Casi no hay aparatos tecnológicos: sólo una tele -y los celulares- en el cuarto de Ariel y Gloria. En el cuarto de Lola predomina el color lila, en el de los chicos el azul y verde. En ambos cuartos encuentro una numerosa cantidad de juguetes y de osos. En el de servicio, Gloria se encarga de lavar la ropa, a veces le pide ayuda a Lola. La parte alta tiene dos momentos de activación en el día: las mañanas y las noches. Es la parte del descanso y del trabajo, al menos del de Gloria. Con el transcurrir del día, va siendo mayor el tiempo en esta planta. En la tarde-noche, Gloria y Ariel les dicen a los más grandes, Nicanor y Lola, que tienen que bañarse, mientras Santiago es acompañado por alguno de los dos. El espacio está determinado estructuralmente y las puertas abren y cierran momentos, conversaciones y relatos. La escalera es la intermediaria de estos dos cosmos de arriba y abajo.

Para Gloria, su casa y las cosas que están allí remiten a modo de ser y estar en el mundo estrechamente orientado a su posición social. La valoración de lo que tiene y cómo mantenerlo se organiza más con relación a una lógica funcional y menos a una lógica de tipo estética. Un ejemplo de ello fue la forma de "resolver» la salida del cable del aire acondicionado y el agujero que estaba allí con el cuadro que le regaló su hermana. Es importante destacar esto porque en su casa los objetos pueden adoptar significaciones ambiguas y sus funciones son dinámicas de acuerdo con esa "casa practicada». De igual manera, lo que Gloria considera valioso en la casa se vincula con la concepción de Haedo «tranquilo, sociable», en donde la limpieza y la tradición emergen como formas del «bienestar material» (material wealth) ${ }^{26}$ (Miodownik, 2013). Es decir, el conjunto de bienes que conforman la cultura

${ }^{26}$ Una traducción posible de este término puede ser «riqueza material», pero considero que la noción de bienestar provee de mayor elasticidad a este término, más si tenemos en cuenta los pro- 
material de su casa, en parte, garantizan ese «vivir bien» y, para Gloria, «segura» en esta localidad. Este bienestar, de manera más integral, se ve acompañado por artefactos y decisiones arquitectónicas que median tales experiencias y sensaciones: sea por la cámara que controla el acceso a su casa, el paredón de concreto que pone el límite entre el adentro y el afuera con la localidad o la enorme puerta de madera maciza que termina por establecer una distancia con el espacio público; como un modo específico de experimentar lo propio «sin riesgos». En este orden de cosas es que identifico cierta contigüidad entre lo deseable para su localidad y lo proyectado para su casa. Dicha continuidad se encuentra garantizada por el lugar que ha elegido para vivir $\mathrm{y}$, del mismo modo, de acuerdo con los vínculos sociales que establece la familia producto de la sociabilidad local, complementariamente articulada por la elección educativa para sus hijos e hija. Las biografías de Gloria y Ariel están estrictamente relacionadas con su profesión y educación de la religión católica y los valores morales, con una retroalimentación dinámica en relación con la morfología urbana encapsulada de Haedo. Con esto refiero a los lazos que pueden establecerse entre la participación de la familia en variadas dinámicas de sociabilidad en Haedo -y en Palomar-que contribuyen al establecimiento de cierto orden moral diferencial (Duarte y Gomes, 2008) en diálogo con un tipo de experiencia que modula ciudadvivienda y prescribe sus elecciones. Siguiendo este horizonte, la previsión del tiempo, su organización, las pautas de aprovisionamiento y la planificación forman parte de sus vidas y de su cotidiano.

Gloria y Ariel prefiguran un futuro para la familia. Las decisiones diarias, la rutina, la economía de la casa, la gestión de la cocina y los bienes y su propio negocio toman parte de esta figura del futuro. Su casa no es un espacio más, sino el espacio en donde se condensa una temporalidad más amplia -el futuro- y formas de gestión de la cotidianeidad que hacen raíz en la figura de Gloria: principal garante y cuidadora del habitar de esta familia. Es en esa organización de la institución familia donde Gloria provee de formas prácticas de gestionar y performar el futuro de cada uno de sus miembros gestionando su propia subjetividad. En este punto, siguiendo el trabajo de Han (2011) considero fértil poder pensar en la fenomenología de la espera ("phenomenology of the waiting») como un lugar de producción de sentidos y de exposición de los usos. Es decir, la configuración familiar en la casa implica el cumplimiento de diversos tipos de roles sociales. Gloria, como muchas mujeres, es central en este proceso de asegurar un tipo de reproducción familiar y de valores conforme a lo propio, pero también a lo apropiado. Su gestión doméstica resulta significativa a los fines de producir un horizonte de lo deseable y de lo posible. Cierto es que, como vimos a lo largo del artículo, la casa es una actividad de tiempo completo.

cesos contemporáneos de adquisición y apropiación material que se despliegan como parte de una narrativa global más fluida sobre la adaptabilidad, la flexibilidad y el cuidado del $y o$. 
Comencé este artículo con una cita de Ambriz Aguilar (2009), quien loa el carácter material y simbólico de la casa, ponderando esa casa practicada. El título de este trabajo alude a dos características que sobrevuelan este análisis. Cautiva insinúa que la casa aún constituye un terreno de interrogantes e incertidumbres poco aprehensibles en ciertas investigaciones si no se tiene en cuenta su carácter vivo y practicado. Dinámica, por su carácter variable, que de acuerdo con el emplazamiento de la casa toma formas específicas.

A partir de Gloria y su familia en Haedo, vimos cómo la elección del habitar se ve sugestionado por experiencias previas conforme a la sociabilidad y a la localidad en un lugar determinado. En ese proyecto de largo plazo, la casa se torna una materialidad vital que posibilita la organización del bienestar. Este bienestar se traduce en diversas elecciones materiales que buscan asegurar la vida "puertas adentro». Aun la diversidad de experiencias, en el caso de esta familia las redes familiares y de sociabilidad resultan significativas para vertebrar este habitar. En este artículo, me interesaba presentar el modo en que un habitar contemporáneo se articula con decisiones que hacen a la vida cotidiana de las personas y aquello que es o no deseable. En este escenario, la figura de Gloria es vital para asegurar un conjunto de prerrogativas. Con relación a esto último, esbocé cómo la espera se transforma en un estado activo de habitar y producir sentidos respecto de la vida propia y la de terceros/as.

Como vimos, las formas de habitar los espacios y significarlos se ven atravesadas por las biografías y geografías de sus habitantes, en donde la experiencia de la familia de Gloria no es la excepción. Este escrito no hace más que deslizar interrogantes respecto a la cultura material, pero también respecto a procesos de significación más amplios donde ella entiende sus decisiones. Cierto es que «no nos encontramos frente a términos estables, sino a conceptos y prácticas en constante mutación, cuyas nuevas expresiones es necesario registrar y conocer» (Ballent y Liernur, 2014: 23). En parte, la pregunta por las formas de vida, la experiencia social y la relación con la naturaleza son motores del devenir disciplinar en humanidades y ciencias sociales. Como formas de espacializar las relaciones sociales que responden tanto a elecciones personales como a tramas familiares que se articulan con la zona en la que se vive tanto como en lo que se proyecta para sí y para otros. Como vimos, la vivienda y su cultura material aún edifica gran parte de la cotidianidad de las personas tanto como sus vínculos sociales. 


\section{REFERENCIAS BIBLIOGRÁFICAS}

Авоу, R. (2008.) «Arquitecturas de la vida doméstica. Familia y vivienda en Buenos Aires, 19141960». Anuario IEHS (23): 355-384.

ACUMAR (2014). «Observatorio Unidad Sanitaria Ambiental de Morón». Informe sociodemográfico $y$ de salud del Partido de Morón. Noviembre.

Ambriz Aguilar, C.E. (2009). «Texto tomado. Análisis narratológico de 'Casa tomada' de Julio Cortázar». Espéculo, Revista de Estudios literarios. Universidad Complutense de Madrid (42).

Arizaga, M.C. (2000). «Murallas y barrios cerrados. La morfología espacial del ajuste en Buenos Aires». Nueva Sociedad, (166): 22-32.

Arizaga, M.C. (2005). «La construcción del gusto legítimo en el mercado de la casa». Bifurcaciones, (5), s/n.

Arizaga, M.C. (2017). Sociología de la Felicidad: autenticidad, bienestar y management del yo. Buenos Aires: Biblos.

Balandier, G. (1994). El poder en escenas. De la representación del poder al poder de la representación. Buenos Aires: Paidós.

Ballent, A. y Liernur, J.F. (2014). La casa y la multitud: vivienda, politica y cultura en la Argentina moderna. Buenos Aires: Fondo de Cultura Económica.

Blanco Esmoris, M.F. (2019). «¿La indeterminación del orden binario? Notas descriptivas para pensar La casa o el mundo dado vuelta de Pierre Bourdieu en una etnografía contemporánea». Cuadernos del Centro de Estudios en Diseño y Comunicación, (88): 111-127. Capital Federal: Cuadernos del Centro de Estudios en Diseño y Comunicación-Universidad de Palermo.

Bonfiglio, J.I., Vera, J. y Salvia, A. (coord.) (2008). Condiciones materiales de vida. Hábitat, pobreza y desigualdad en los hogares urbanos de la Argentina (2010-2017). Ciudad Autónoma de Buenos Aires: Educa.

Castells, M. (2001). La Era de la Información: Economía, Sociedad y Cultura. Madrid: Alianza Editorial.

Cosacov, N. (2017). «El papel de la familia en la inscripción territorial. Exploraciones a partir de un estudio de hogares de clase media en el barrio de Caballito, Buenos Aires». Población \& Sociedad, vol. 24 (1): 35-65.

Devoto, N.P. (1967). «Haedo, 1902». La Tribuna, especial agosto.

Duarte, L. y Gomes, E. (2008). Três Famílias. Identidades e Trajetórias Transgeracionais nas Classes Populares. Rio de Janeiro: Editora FGV.

Guber, R. (2001). La etnografía, método, campo y reflexividad. Bogotá: Grupo Editorial Norma.

HAN, C. (2011). «Symptoms of another life: time, possibility and domestic relations in Chile's credit Economy». Cultural Anthropology (26) 1.

Infonegocios (2013). «Apellido de café», entrevista a Martín Cabrales -tercera generación de la empresa líder del rubro-, 3 de junio, recuperado de https://infonegocios.info/in-semanal/ apellido-de-cafe. Última consulta: 29/04/2020.

INGOLD, T. (1995). «Building, dwelling, living: How animals and people make themselves at home in the world», en M. Strathern (ed.), Shifting Contexts. London: Routledge. 
Kamitz, R. (2015). Condominios Urbanos. Análisis sobre el polo residencial de Ramos Mejía, Haedo y Villa Sarmiento. Alternativa para la revalorización de enclaves urbanos en áreas potenciales para el desarrollo inmobiliario (tesis de maestría). Belgrano: Universidad de Belgrano.

Martínez, E. (2014). «Configuración urbana, habitar y apropiación del espacio». XIII Coloquio Internacional de Geocritica. Barcelona: Universidad de Barcelona.

McDowell, L. (2000). Género, identidad y lugar. Madrid: Eds. Cátedra.

Miller, D. (ed.) (2001). Home possesions: material culture behind close doors. UK: Bloomsbury Academic.

Miller, D. (2005) Materiality. Duke: Duke University Press.

Miller, D. (2008) The comfort of things. Cambridge: Polity Press.

Miodownik, M. (2013). Stuff Matters, The Strange Stories of the Marvellous Materials That Shape Our Man-Made World. Londres: Penguin.

Pérez, I. (2012). El hogar tecnificado. Familias, género y vida cotidiana 1940-1970. Buenos Aires: Biblos.

Segura, R. (2015). «La imaginación geográfica sobre el conurbano. Prensa, imágenes y territorio», en G. Kessler (dir.), Historia de la provincia de Buenos Aires: El Gran Buenos Aires. Ciudad Autónoma de Buenos Aires: Edhasa, Gonnet, UNIPE, Editorial Universitaria.

VISAcovsky, S. (2008). «Estudios sobre 'clase media' en la antropología social: una agenda para la Argentina». Avá Revista de Antropología, (13): 9-37.

Wortman, A. (2001). «Globalización cultural, consumos y exclusión social». Nueva Sociedad (175): 134-142. 